\title{
Moral Hazards and Effects of Enhanced Monitoring Systems in Online Labor Markets
}

\author{
Chen Liang \\ Arizona State University \\ chen.liang.4@asu.edu
}

\author{
Yili Hong \\ Arizona State University \\ hong@asu.edu
}

\author{
Bin $\mathrm{Gu}$ \\ Arizona State University \\ bin.gu@asu.edu
}

\begin{abstract}
This paper investigates how IT-enabled monitoring systems mitigate moral hazard in an online labor market and their effect on market competition. We exploit a quasi-experiment at Freelancer when it introduced an IT-enabled monitoring system in 2015. We use a difference-in-differences (DID) approach to identify the treatment effect of the monitoring system on employer contractor choice, market competition, and employer surplus. We found that the IT-enabled monitoring system lowers the employers' willingness to pay the reputation premiums. Meanwhile, comparing the trend of the control group, the IT-enabled monitoring system raised the employer surplus in hourly projects and increased the number of bids. Our result suggests that IT-enabled monitoring systems have a significant effect on alleviating moral hazards, reducing agency costs, and facilitating market competition.
\end{abstract}

\section{Introduction}

Information technology has a profound effect on firm boundaries [1-3]. As IT reduces transaction costs, firms increasingly resort to market mechanisms such as outsourcing and offshoring for service procurement. Online labor markets are at the forefront of this phenomenon. In the past few decades, online labor markets have undergone a tremendous growth. For example, by December 2015, there were over 9 million projects posted in Freelancer, one of the most prominent online labor markets, and about 17 million registered users have used the platform to look for job opportunities.

Despite the tremendous growth, online labor markets have their limitations due to information asymmetry and agency problems between contractors and employers, amplified by spatial and temporal separations $[4,5]$. Moreover, because the monitoring and control mechanisms to ensure work performance [6] are weaker and indirect in online labor markets [7], it's easier for opportunistic contractors to shirk and misrepresent their effort. A common solution to this agency problem is the use of fixed-price contracts, where payment is outcomedriven. That is, contractors can't get the fixed payment until they complete the projects successfully [8]. Therefore, the contractors' dominant strategy for is to complete the projects, which alleviates the moral hazard issues [9].

An alternative to fixed-price contracts is hourly contracts, where payment is determined based on the amount of hours the contractors have spent and the hourly wages [8]. While hourly contracts provide a stronger incentive for better project performance [8] and have better applicability to complex contexts [10, 11], they also offer the contractors monetary incentives to shirk. Therefore, information asymmetry in online labor markets renders moral hazard problems of hourly projects more prominent [10].

To alleviate moral hazard issues in online labor markets, many online labor platforms started to provide automatic tracking functionality [12]. For instance, Freelancer released an enhanced tracking feature in its application since August 2nd, 2015. In this study, we analyze how such an enhanced monitoring system would influence employers' and contractors' behavior and welfare. In particular, we address three research questions: First, do monitoring systems help alleviate the moral hazard problems, and thus lower employers' preference for reputable bidders? Second, if monitoring systems indeed change employer preference, how does such a change influence the market competition? Third, given its impact on the market competition, how do monitoring systems affect employer surplus?

We propose a number of hypotheses based on the agency theory and we expect the enhanced monitoring systems to have a significant effect on alleviating the moral hazard problems in hourly contracts relative to fixed-price contracts. We analyze how the enhanced monitoring feature affect both the demand and the supply sides of the hourly project market. Our identification is based on a quasi-natural experiment (release of enhanced offline tracking feature in the 
Freelancer application), in which we consider hourly projects as the treatment group and fixed-price projects as the control group. With a large dataset including 36,407 projects posted on Freelancer, we use a difference-in-differences (DID) approach to identify the treatment effect of the system introduction on employer contractor decision, market competition, and employer surplus. Our analysis suggests that after the introduction of the enhanced monitoring systems, employers show less preference for bidders with high-reputation, and thus be less willing to pay the reputation premiums. Further, this treatment fosters market competition for hourly projects by increasing number of bids on hourly contracts by $15.7 \%$ and increases the employer surplus in hourly projects.

Our paper makes three key contributions. First, our paper is a large-scale empirical research to investigate the effect of IT-enabled monitoring systems on employer and contractor decisions in online labor markets, which extends prior research on the contract design in labor markets $[9,13,14]$. Second, this paper contributes to research on reputation systems in online platforms. While the previous literature focused on the effect of reputation systems on agency problems $[7,15$, 16], our study investigated the effect of monitoring systems and their interaction with reputation systems. Third, this study deepens our understanding of the design of online labor markets $[4,5]$, specifically, we extend the understanding of designing IT-enabled monitoring systems to alleviate moral hazard problems, reduce agency costs, and facilitate competition in online labor markets.

This paper proceeds as follows. Section 2 introduces the theoretical background followed by the hypotheses development section. In Section 3, we introduced the data description and empirical models. Finally, we discussed the overall findings and implications.

\section{Theoretical background}

\subsection{Online labor markets}

Online labor markets, which aims to facilitate the procurement of labor services from all over the world [4], have grown dramatically during recent years. But information asymmetry persists in such markets because contractors' qualities and their actual effort levels are hard to observe. Therefore, agency problems are prevailing in online labor markets.

The first type of common agency problems that has attracted attention from both the practice and academic scholars is the adverse selection problem. Adverse selection problems are caused by the asymmetric distribution of information and the difficulties in evaluating the contractors' capabilities and skills [5, 17]. In order to alleviate the adverse selection problems, most online labor markets provided the reputation history of contractors by tracking their previous project performance. There is a stream of research examining the effect of reputation systems on alleviating the adverse selection problems and employers' awarding decisions. First, a good reputation increases the probability of being awarded. For the entry-level contractors, the review information posted by previous employers or the platform can significantly help them to get better employment, ceteris paribus [18]. Additionally, thanks to the good reputation (comments or ratings), contractors can obtain price premiums and get more employment [20]. However, it's also reported that rating information driven from public feedbacks tends to inflate [7]. Apart from ratings and reviews information, the third-party certification is also found to be one of the optional signaling mechanisms [21]. On the whole, the previous literature suggests that the reputation system and third-party certification system helps to address the adverse selection problem.

Once the contractors are awarded, the other type of agency problems, the moral hazard problem follows. Moral hazard refers to the case when the contractor is not motivated to maximize the employer's utility and opportunistically reduces his or her effort [17]. Such shirking problems are usually caused by the asymmetric effort information and the misalignment between the principals' and agents' interests. Online labor markets are prime examples of markets which are subject to the moral hazard problems because of the spatial and temporal separation and the lack of effective monitoring systems. However, no prior research has examined how reputation systems and monitoring systems might interact and subsequently influence employers' and contractors' behavior.

\subsection{Contract types}

In the software outsourcing industry, there are two common contract types, namely, fixed-price contracts and time and materials contracts [22]. Fixed-price contracts are outcome-based, which means that the agent gets a fixed payment based on the amount of output [8]. On the other hand, in time and materials contracts, the payment should be calculated based on the agent's time in the work process [8]. According to the literature on transaction cost economics [23], contract design depends on the tradeoff between potential renegotiation costs of fixed-price contracts and the costefficiency losses of time and materials contracts [23]. Based on the existing literature, many factors might influence the contract choice, such as firm size [24], reputation [22], project risk [24], business familiarity 
[25], and to what extent the outcome is sensitive to the agent's or the principal's effort [26]. Compared to time and materials contracts, fixed-price contracts usually incur higher costs for information collection and negotiating the provision; and higher maladaptation and renegotiation costs [27]. On the other hand, time and materials contracts usually lead to higher ex-post monitoring and auditing costs [10, 11, 23, 27].

Some researchers consider the trade-off between two types of contracts as a "make-or-buy" decision [10]. The "buy" choice, corresponding to the fixed-price contract, means the external contractor cannot get the fixed payment until he or she accomplishes the project. Such a choice is preferred when the task is easy to define. On the other hand, the "make" choice, which is corresponding to the time and material contract, is similar to the process of self-production. On the incentive side, for the "buy" choice, contractors are contracted for the final project outcomes, which provides sufficient motivations for them to efficiently spend efforts and time on the projects. However, for a "make" choice, contractors' payments are based on the amount of time they have spent on the projects. Without an effective monitoring system in use, contractors might opportunistically shirk, especially when their effort could not be well monitored. Therefore, moral hazard problems are more severe in a "make" choice [9]. However, a "make" choice could contribute to better performance and higher client validation quality than the other if the monitoring process is effective and efficient [11]. In addition, there are other optional contract types, including performance-based contracts, profit-sharing contracts [11], and hybrid contracts [22]. Our paper focuses on the comparison between the fixedprice and time and materials contracts because they are the only two contract type options in most dominant online labor markets.

\subsection{Monitoring and reputation systems}

Monitoring systems and reputation systems are both effective mechanisms to alleviate moral hazard problems. Monitoring aims to lower the information asymmetry by providing more information regarding the actions of contractors, while reputation systems provide a signal of contractors' future performance based on their performance ratings entered by previous employers [28]. It's found that both the monitoring system and the reputation system can independently mitigate moral hazard [29-32].

On the one hand, monitoring turns the individual information about contractors' actual effort into information that the principals could observe. Hence, it can increase the likelihood of "shirking" going noticed, and then improve the contractors' effort [32]. There is a large body of research supporting that, monitoring increases the contractors' effort and leads to better performance [29-31]. On the other hand, reputation connects contractors' performance in the present project with the further probability of getting hired. Therefore, reputation provides a stimulus to motivate contractors to spend more effort on projects [7]. To avoid getting a bad reputation, the contractor will be less likely to shirk, which implies that the reputation system acts as a sanctioning mechanism [15]. However, the monitoring system and the reputation system might not work independently, which implies that there might be some unexpected interaction relationship between two aforementioned mechanisms [33, 34]. Since both a welldesigned reputation system and a precise monitoring system are effective tools to mitigate moral hazard, the introduction of an enhanced monitoring system might lower the employers' reliance on the reputation system, and thus weaken the effect of the reputation system. Therefore, in such cases, the monitoring systems might substitute for the reputation systems in reducing contractors' shirking behavior. However, none of the previous IS studies has investigated the potential interaction between monitoring systems and reputation systems. In summary, both the monitoring system and the reputation system help to alleviate moral hazard [2931], but it's still unclear whether there is a substitution relation between them.

\section{Hypotheses development}

\subsection{Partial substitution between monitoring and reputation}

If the risk of moral hazard is high, the employer prefers to choose the contractor with a high reputation, because the reviews and feedbacks entered by previous employers help to alleviate information asymmetry and act as signals of the reputable contractor's future effort level [28]. However, when an enhanced monitoring system is available, the functionality of the reputation system might be partially substituted by the monitoring system because the monitoring system can lower the contractors' reliance on reputation signals to increase the contractors' effort and lower cost uncertainty. Firstly, because of the unobservable contractors' actual effort, employers consider the contractor's reputation as the signal to identify the type of the contractor [19]. For example, from the perspective of employers, a reputable contractor usually be thought as an agent with high expected effort, which suggests employers' preference for the contractors with a high reputation [18]. However, when the enhanced monitoring tool is available, the employers can verify the contractors' actual effort and 
only continue the employment if they find that the contractors' levels of effort are acceptable. Hence, by using an efficient monitoring system, the employers don't need to emphasize the contractors' reputation too much because they can ensure the awarded contractors' actual effort through monitoring [16]. Secondly, monitoring systems provide more detailed information about the contractors' performance and how to improve it, so that it can help to save time and decrease the cost uncertainty of hiring inexperienced contractors. Before the enhanced monitoring tool is introduced, the employers might prefer for contractors with a high reputation because of their higher expected effort and their smaller cost uncertainty (variance) [8]. However, with the enhanced monitoring systems in use, employers can have better information about contractors' actual performance and instruct them to perform more efficiently. In other words, no matter the contractors have a high reputation or not, the employers can keep the cost uncertainty at a low level by ensuring that contractors are making satisfactory progress. This improvement suggests that the monitoring systems narrow the difference between the high reputable contractors and the low-reputable ones in terms of project cost uncertainty. All in all, monitoring systems lower employers' worries about the contractors' shirking behavior and high cost uncertainty, and also substitute for the signaling effect of the reputation systems. Therefore, we propose the following hypothesis:

H1: After an enhanced monitoring tool is available, employers of hourly projects will place a less emphasis on worker reputation.

\subsection{Monitoring and market competition}

Now considering the effect of enhanced monitoring systems on the supply side, we expect that more contractors will be interested in hourly projects because of the lower entry barrier, as the reputable contractor's past reputation on work efforts becomes substitutable. On the one hand, the monitoring system lowers the entry barrier by lowering employers' reliance on the reputation to mitigate moral hazard problems. Before the monitoring system is available, the reputation acts as an entry barrier for relatively inexperienced contractors who have not yet built their reputation on the online labor markets. Consequently, those contractors with a good reputation can get better employment while acquiring a high rent [18]. However, after the introduction of the enhanced monitoring systems, employers can obtain the direct information about contractors' effort from the real track records rather than the past performance, which implies the entry barrier based on reputation prominently drops [33]. Therefore, inexperienced contractors are more likely to bid for those hourly projects. On the other hand, based on the logic of the substitution relationship between the monitoring system and reputation we explained earlier, the subsequent change in employer preference leads to a smaller difference between the contractors with little platform experience and those experienced contractors. Therefore, the additional value due to a high reputation will be greatly removed, and the low-reputable contractors' work will serve as a closer substitute for the high-reputable contractors' work. In such cases, the market becomes more competitive. To sum up, we expect that the monitoring system facilitates competition and formalize the next hypothesis as follows:

H2: After an enhanced monitoring tool is available, the number of bidders of hourly projects will be higher.

\subsection{Monitoring and employer surplus}

In the same vein, because of the potential substitution relationship between monitoring systems and reputation systems, employers will be less willing to pay the price premiums, especially the reputation premiums. From the perspective of the supply side (contractors), reputable contractors tend to milk their reputation by charging the price premiums [20]. However, such price premiums don't guarantee higher quality [35]. In such cases, reputation helps to foster product nonprice differentiation of the reputable contractors' service. Meanwhile, from the perspective of the demand side, because of the potential moral hazard problems in the online labor markets, employers are uncertain about the effort of contractors without the monitoring systems. Therefore, employers would pay price premiums to the reputable contractors [36] and even consider the reputation premiums as the cost of avoiding the shirking behavior [37]. However, since the monitoring systems can alleviate the moral hazard problems and partially substitute for reputation systems, there is no need for employers of hourly projects to pay such reputation premiums to address the moral hazard problems. Moreover, our argument is also supported by Allgulin and Ellingsen's [38] finding that when monitoring is very precise, efficient and cheap, the agent tends to become less capable of earning rents and get the minimal utility. Therefore, when the agent can be monitored perfectly, contractors' effort level will be paid at their corresponding reservation wage [38]. Additionally, this argument is also consistent with the Efficiency Wage Model, which predicts that intensive monitoring leads to low wage premiums [39-41]. Since employers no longer need to pay reputation premiums, we expect that employer surplus will be higher after the 
introduction of a monitoring system. So we propose the following hypothesis:

H3: After an enhanced monitoring tool is available, employers of hourly projects will enjoy a higher surplus.

\section{Research methodology}

\subsection{Date source}

Our unique dataset comes from www.freelancer.com (Freelancer), which is one of the largest online labor market platforms. In 2015, it was awarded as 2015 Best Employment Website and 2015 Best Professional Services Website. In Freelancer, the employer can pose his or her project description and project budgets. By showing the total project budget, the employer indicates that this project adopts a fixed-price contract. If the unit of the project budget is dollars per hour, it implies that the employer will make a time and materials contract and then the contractor will get paid for his or her hourly work.

Typically, a project will open for bidding for a week and any contractor who is interested in it can bid to win the project. Before the bidding period expires, the employer can review bidders' basic information, such as their nationality, skills, etc. Moreover, Freelancer also provides bidders' previous project experience and their former employers' ratings and comments. Once the employer finds the candidate who satisfies him or her the most, he or she could award the project to that contractor. Our dataset from Freelancer including the project information and user information from Oct $1^{\text {st }}$, 2013 to February $29^{\text {th }}, 2016$. The whole sample includes 36407 projects posted on Freelancer, and 1620 of them have finally been awarded to contractors. The definition of the project-level variables is shown in Table 1. Our dataset includes the following attributes: 1) project-level information (i.e. project description, project budget, type of contracts, number of bidders, average bid price and so on); 2) user-level information (i.e. ratings, number of reviews, nationality, etc.).

\section{Table 1 Definitions of related variables}

\begin{tabular}{|l|l|}
\hline Variable & Variable definition \\
\hline Num_Bid & $\begin{array}{l}\text { total number of bids received by the } \\
\text { project }\end{array}$ \\
\hline Budget_Min & $\begin{array}{l}\text { the minimum budget set by the } \\
\text { employer }\end{array}$ \\
\hline Budget_Max & $\begin{array}{l}\text { the minimum budget set by the } \\
\text { employer }\end{array}$ \\
\hline Employer_Developed & $\begin{array}{l}\text { whether the employer comes from a } \\
\text { developed country }\end{array}$ \\
\hline Project_title_length & $\begin{array}{l}\text { number of characters in the project } \\
\text { title }\end{array}$ \\
\hline Desc Length & the length of project description \\
\hline
\end{tabular}

\begin{tabular}{|l|l|}
\hline Num_Employerreview & $\begin{array}{l}\text { total number of reviews received by } \\
\text { employers }\end{array}$ \\
\hline Employer_Rating & $\begin{array}{l}\text { average rating score received by the } \\
\text { employer }\end{array}$ \\
\hline NDA & $\begin{array}{l}\text { a dummy variable( } 0,1),=1 \text { if the } \\
\text { employer and the bidder have } \\
\text { assigned a NDA contract to protect } \\
\text { the employer's right }\end{array}$ \\
\hline Featured & $\begin{array}{l}\text { whether the project is a featured } \\
\text { project }\end{array}$ \\
\hline Nonpublic & $\begin{array}{l}\text { A dummy variable }(0,1),=1 \text { if the } \\
\text { project is an non-public project }\end{array}$ \\
\hline Fulltime & $\begin{array}{l}\text { A dummy variable(0,1), =1 if the } \\
\text { project is an fulltime project }\end{array}$ \\
\hline Language_en & $\begin{array}{l}\text { A dummy variable(0,1), =1 if the } \\
\text { project is described in English }\end{array}$ \\
\hline
\end{tabular}

\subsection{Identification: a quasi-natural experiment}

As mentioned before, the information asymmetry problem has been a serious issue, especially for hourly projects. Because the risk allocation of an hourly project is mainly on the principal (the employer), the tradeoff between monitoring costs and the uncertainty or risk of outcome always troubles the employer [8]. On August $2^{\text {nd }}, 2015$, Freelancer released an IT-enabled monitoring system to reduce the difficulty of monitoring. Such a new IT artifact is a prime example of the IT-enabled behavior-based control tool. The enhanced monitoring system can confidently keep a record of the project process even with an unstable Internet connection, which means that employers didn't need to keep checking the project process frequently because the monitoring records would be automatically archived. Therefore, this IT-enabled monitoring system alleviates the concerns that employers may lose track of project progress, and thus lowers monitoring costs. According to the comparisons across contract types, the ex-post costs of monitoring and auditing for hourly contracts are higher $[10,11,23,27]$ and the risk is mainly allocated on employers. Therefore, the IT-enabled monitoring system should have a stronger effect on hourly projects than fixed-price ones. Here, we regard fixed-price projects as the control group and examined the effect of the enhanced monitoring systems on hourly projects. Because the fixed-price projects in the control group can efficiently capture the effect of economic cycles or platform characteristics, we can identify the treatment effect of the enhanced monitoring systems on the number of bids and employer surplus.

\section{Measures and models}

\subsection{Conditional Logit Model}


Assuming that employer choice probabilities satisfy the independence irrelevant alternatives (IIA) property [42], we estimated the probabilities of employers' awarding decision based on a conditional logit model. An employer chooses one contractor from all the bidders, and the probability of one bidder being awarded is $\operatorname{Pr}$ (bidderij=1), which is depending on the employer's utility from hiring him or her.

$$
U_{i j}=\alpha X_{i j}+\beta B_{j}+\gamma P_{i}+\varepsilon_{i j}
$$

where $X_{i j}$ denotes a set of project-bidder paired characteristics, such as the price premium of each bid. $P_{i}$ indicates a set of time-invariant project characteristics, such as project budget, the length of description, etc. $B_{j}$ means the bidders' related characteristics, such as bidders' ratings, whether he or she is from a developed country and so on. $\varepsilon_{i j}$ follows the i.i.d. type-I extreme value distribution [42]. Since the Conditional Logit Model is similar to a fixed-effect logit model [43], $P_{i}$ doesn't include any within-group variations. So it will not influence the conditional probability. Based on our theoretical background, we extended the latent utility model as follows:

$$
\begin{aligned}
& \text { Price_Premium }_{i j}=\frac{\left(\text { Bid_Price }_{i j}-\text { Budget_Min }_{i}\right)}{\text { Budget_Min }_{i}} \\
& U_{i j}= \alpha \text { Price_Premium } \\
& \times \text { After } \times \text { Hourly }+ \\
& \beta \text { Bidder_Rating } \\
&+ \text { After } \times \text { Hourly }+\gamma P_{i} \\
&+ \text { Controls }+\varepsilon_{i j}
\end{aligned}
$$

where $\alpha$ is a $4 \times 1$ matrix of coefficient estimates and each row is corresponding to one of the following four groups: 1) After $=0$, Hourly $=0$; 2) After $=$ 1, Hourly $=0$; 3) After $=0$, Hourly $=1$; 4) After $=1$, Hourly $=1$. Since there exist strong linear correlations between the bidders' ratings of different dimensions, we employed the Principal Component Analysis (PCA) approach to reduce dimensions and generated four components representing four kinds of ratings, including 1) PC1: Quality_of_Contractor; 2) PC2: Effort_at_Work. Therefore, $\beta$ is a $4 \times 2$ matrix of coefficient estimates. Each of row represents the coefficient estimate result of four components for each group.

\subsection{DID models}

In order to test Hypothesis 3, we create a relative employer surplus measure Employer_Surplus, which measures the relative percentage of employer surplus with respect to the maximum of budget. Here, the employer surplus means the gap between the maximum of project budget and the final awarded bid price. If the price is just equal to the employer's Willingness To Pay (WTP), that is, the maximum of budget, he or she is indifferent between hiring and not hiring and the employer surplus will be zero.
Employer_Surplus

$$
=\frac{\left(\text { Budget_Max }_{i}-\text { Award_BidPrice }_{i}\right)}{\text { Budget_Max }_{i}}
$$

Based on our dataset and research design, we estimated the treatment effect based on the Differencein-Difference (DID) model [44]:

$$
\begin{gathered}
\text { Employer_Surplus }_{i}=\alpha+\beta_{1} \text { After }_{i}+\beta_{2} \text { Hourly }_{i} \\
+\beta_{3} \text { After }_{i} \times \text { Hourly }_{i}+v_{i}+\varepsilon_{i} \\
\text { Num_Bids }_{i}= \\
\beta_{3} \text { After }_{i} \times \beta_{1} \text { Hourly }_{i}+v_{i}+\varepsilon_{i}
\end{gathered}
$$

In the model, the dependent variable is the total number of bids for each project i, Num_Bids $s_{i}$. After $r_{i}$ is the dummy variable indicating whether the project is posted after August $2^{\text {nd }}, 2015$. Contract type is indicated by Hourly ${ }_{i}$, which equals to 1 if it is an hourly project, and equals to 0 otherwise. The interaction term between After $_{i}$ and Hourly $_{i}\left(\beta_{3}\right)$ thus identifies the heterogeneous effect of the availability of the enhanced monitoring systems on fixed-price projects and hourly ones. To control for the heterogeneity of projects, we also added many project characteristics and employer characteristics $\left(v_{i}\right)$ into the DID models and $\varepsilon_{i}$ denotes the error term.

\section{Empirical result}

\subsection{Employer preference and surplus}

Based on the result of the Conditional Logit model, we can find that before the enhanced monitoring system was available, both Quality_of_Contractor and Effort_at_Work had significant positive effects on the odds of being awarded in hourly projects. Given that $\beta_{\text {Effort }}$ was estimated as 0.415 and $\beta_{\text {Price_Premium }}$ as 1.835 , employers were willing to pay up to more $22.6 \%$ of Budget_min for 1 unit increase in the Effort at Work component, which means that reputable bidders could earn high price premiums without the enhanced monitoring system in use. However, after the enhanced monitoring system was released by Freelancer, neither the coefficient of Quality_of_Contractor nor that of Effort_at_Work is significant. Additionally, the coefficient of Price Premium is significantly negative. In such case, employers are only willing to pay more $7.7 \%$ of Budget_min in order to hire a bidder with 1 unit higher in the Effort_at_Work component, which implies that employers are less willing to pay high price premiums to the bidders with a high reputation than they were before. Hence, Hypothesis 1 is also supported. We also retested Hypothesis 1 with the linear Fixed Effect model, and the results are qualitatively the same. Moreover, since employers are less willing to pay the price premiums, they can enjoy a higher surplus than 
before. According to the result of the DID model, the interaction term between the after and hourly dummies is significantly positive, which suggests that employers can reap a higher surplus after the implementation of monitoring systems.

\section{Table 2. Estimation results of the Conditional} Logit Model

\begin{tabular}{|c|c|}
\hline DV: Project_awarded & Coefficient \\
\hline Fixed_price, Before*Quality & $(0.057)$ \\
\hline Fixed_price, After*Quality & $0.090 * *(0.037)$ \\
\hline Hourly, Before*Quality & $0.052 \quad(0.151)$ \\
\hline Hourly, After*Quality & $0.005 \quad(0.081)$ \\
\hline Fixed_price, Before*Effort & $0.298 * * *(0.106)$ \\
\hline Fixed_price, After*Effort & $0.409 * * *(0.080)$ \\
\hline Hourly, Before*Effort & $0.415 * *(0.192)$ \\
\hline Hourly, After*Effort & $(0.235)$ \\
\hline Log_b_count_rating & $(0.026)$ \\
\hline Fixed_price, Before*Price_premium & $-2.086 * * *(0.397)$ \\
\hline Fixed_price, After*Price_premium & $-1.967 * * *(0.248)$ \\
\hline Hourly, Before*Price_premium & $-1.835 * *(0.863)$ \\
\hline Hourly, After*Price_premium & $-1.845 * *(0.858)$ \\
\hline Bidder_developed & $0.619 * * *(0.097)$ \\
\hline Bidder_belong_company & $(0.064)$ \\
\hline Log_bidder_tenure_month & $(0.062)$ \\
\hline Log_bidder_rank & $-0.316^{* * *}(0.049)$ \\
\hline Log_bid_order_rank & $0.391 * * *(0.043)$ \\
\hline Log_b_hourly_rate & $(0.056)$ \\
\hline Preferredfreelancer & $0.161 * *(0.074)$ \\
\hline Localfreelancer & $(0.184)$ \\
\hline $\mathrm{N}$ & 23,438 \\
\hline Note: a. ${ }^{*} p<0.1 \quad * * p<0.05 \quad * * * p<$ & \\
\hline
\end{tabular}

Table 3. DID estimations of the impact of the enhanced monitoring systems on Employer_Surplus

\begin{tabular}{|c|c|c|c|}
\hline $\begin{array}{l}\text { DV: } \\
\text { Employer_Surplus }\end{array}$ & (1) & (2) & (3) \\
\hline \multirow[t]{2}{*}{ Hourly } & $0.251 * * *$ & $0.270 * * *$ & $0.247 * * *$ \\
\hline & $(5.53)$ & $(5.93)$ & $(5.44)$ \\
\hline \multirow[t]{2}{*}{ After } & $-0.044 *$ & $-0.050 *$ & $-0.064 * *$ \\
\hline & $(-1.68)$ & $(-1.94)$ & $(-2.46)$ \\
\hline \multirow[t]{2}{*}{ Hourly*After } & $0.114^{*}$ & $0.125^{*}$ & $0.109^{*}$ \\
\hline & $(1.73)$ & $(1.89)$ & $(1.67)$ \\
\hline \multirow{2}{*}{ Budget_Max } & $0.110 * * *$ & $0.116^{* * *}$ & $0.107 * * *$ \\
\hline & $(11.86)$ & $(12.20)$ & $(11.13)$ \\
\hline \multirow[t]{2}{*}{ Desc_Length } & & $-0.046 * * *$ & $-0.039 * * *$ \\
\hline & & $(-3.18)$ & $(-2.67)$ \\
\hline \multirow[t]{2}{*}{ SkillsNum } & & -0.020 & $-0.037 *$ \\
\hline & & $(-0.99)$ & $(-1.84)$ \\
\hline \multirow[t]{2}{*}{ Employer_Developed } & & 0.019 & 0.002 \\
\hline & & $(0.75)$ & $(0.07)$ \\
\hline \multirow[t]{2}{*}{ Num_Bid } & & & $0.064 * * *$ \\
\hline & & & $(5.08)$ \\
\hline \multirow[t]{2}{*}{ Intercept } & $-0.239 * * *$ & -0.063 & $-0.180 * *$ \\
\hline & $(-4.86)$ & $(-0.87)$ & $(-2.37)$ \\
\hline $\mathrm{N}$ & 1,620 & 1,620 & 1,620 \\
\hline Adj R-squared & 0.080 & 0.086 & 0.100 \\
\hline \multicolumn{4}{|c|}{$\begin{array}{l}\text { Notes: a. Budget_Max, Desc_Length, SkillsNum, } \\
\text { Employer_Developed, Bid_Value are log transformed. } \\
\begin{array}{lll}\text { b. } * p<0.1 & * * p<0.05 & * * * p<0.01\end{array}\end{array}$} \\
\hline
\end{tabular}

\subsection{Market competition}

Based on the result of DID model, we found that the coefficient of After $\left(\beta_{1}\right)$ is positive, which means that there are more contractors bidding for fixed-price projects than before. This increase in Num_Bids might result from multiple reasons, such as platform popularity, etc. Taking this into consideration, the interaction term $\left(\beta_{3}\right)$ is significantly positive, which suggests that after the IT-enabled monitoring system is available, the increase in Num_Bids of hourly projects is larger than that of fixed-price projects. Therefore, Hypothesis 2 is supported. Overall, our results of the Conditional Logit Model and DID models support all the hypotheses.

Table 4. DID estimations of the Impact of the enhanced monitoring systems on Num Bids

\begin{tabular}{|c|c|c|c|c|}
\hline DV: Num_Bids & (1) & (2) & (3) & (4) \\
\hline \multirow[t]{2}{*}{ Hourly } & $0.310 * * *$ & $0.367 * * *$ & $0.197 * * *$ & $0.201 * * *$ \\
\hline & (3.39) & $(4.07)$ & $(4.88)$ & (5.13) \\
\hline \multirow[t]{2}{*}{ After } & $0.229 * * *$ & $0.211 * * *$ & $0.187 * * *$ & $0.179 * * *$ \\
\hline & (4.37) & $(4.11)$ & (16.45) & $(15.89)$ \\
\hline \multirow[t]{2}{*}{$\begin{array}{l}\text { After } \times \\
\text { Hourly }\end{array}$} & $0.271^{* *}$ & $0.239^{*}$ & $0.168 * * *$ & $0.157 * * *$ \\
\hline & $(2.03)$ & $(1.83)$ & (3.64) & $(3.51)$ \\
\hline \multirow[t]{2}{*}{ Budget_Max } & $0.152 * * *$ & $0.142 * * *$ & $0.139 * * *$ & $0.126^{* * *}$ \\
\hline & $(8.09)$ & $(7.59)$ & $(37.21)$ & $(34.64)$ \\
\hline \multirow[t]{2}{*}{ Desc_Length } & & $-0.118 * * *$ & & -0.113 *** \\
\hline & & $(-4.13)$ & & $(-16.83)$ \\
\hline \multirow[t]{2}{*}{ SkillsNum } & & $0.273^{* * *}$ & & 0.387 *** \\
\hline & & $(6.86)$ & & (40.67) \\
\hline \multirow[t]{2}{*}{$\begin{array}{l}\text { Employer } \\
\text { Developed }\end{array}$} & & $0.275^{* * * *}$ & & $0.304 * * *$ \\
\hline & & $(5.42)$ & & $\begin{array}{l}(27.19) \\
\end{array}$ \\
\hline \multirow[t]{2}{*}{ Intercept } & $1.745 * * *$ & $1.832 * * *$ & $1.882 * * *$ & $1.840 * * *$ \\
\hline & $(17.60)$ & $(12.76)$ & $(86.31)$ & $(55.46)$ \\
\hline $\mathrm{N}$ & 1,620 & 1,620 & 36,407 & 36,407 \\
\hline Adj R-squared & 0.056 & 0.098 & 0.049 & 0.108 \\
\hline \multicolumn{5}{|c|}{$\begin{array}{l}\text { Notes: a. Model (1) and (2) are using only the awarded project } \\
\text { subsample whose awarded bidder is known. Model (3) and (4) } \\
\text { are using the whole project sample; } \text { b. Num_Bids, Budget_Max, } \\
\text { Desc_Length, SkillsNum are log transformed. There are other } \\
\text { project-level characteristics, which are also controlled in the DID } \\
\text { model but their coefficients are not reported in this table. c. * } \\
p<0.1 \quad * * p<0.05 \quad * * * p<0.01 \text {. }\end{array}$} \\
\hline
\end{tabular}

\section{Discussion}

\subsection{Key findings and implications}

In this research, we show the evidence that the introduction of the enhanced monitoring systems can lower the employers' preference for the contractors with a high reputation, facilitate market competition and increase employer surplus. Our estimation results are based on a quasi-natural experiment design with fixedprice projects as the control group and hourly projects as the treatment group. The results of our DID models and the Conditional Logit Model suggest that after the 
enhanced monitoring system is introduced, employers are less willing to pay the reputation premiums, and thus enjoy a higher surplus. This finding implies that there exists a partial substitution relationship between the monitoring system and the reputation system. Moreover, our result also shows that the introduction of IT-enabled monitoring systems facilitates competition by attracting more bids.

Additionally, our study also contributes to several strands in the online labor market literature. First, it is a large-scale empirical research to examine the effect of enhanced monitoring systems on both the demand and supply side of an online labor market. Though the previous literature mainly examining the effect of monitoring systems within a firm [16] or a geographical area [29], our large dataset can be leveraged to test the influence of the monitoring system on the whole online labor market within a certain platform. Such an advantage enables us to identify the ripple effect of the enhanced monitoring systems on the market structure. Second, our study extends the previous literature on the effect of reputation systems in online markets. According to the previous literature on reputation systems, reputation acts as a signal of contractor's future performance [28], and motivates them to spend more effort [7]. However, our result suggests that its effect can be partially substituted by the enhanced monitoring system, which alleviates the moral hazard problems by efficiently providing more precise information about the contractors' effort [29, 45]. Third, this research suggests that the impact of enhanced monitoring systems is not limited to mitigating the moral hazard problems and improving agents' productivity [31]. Our study suggests that the enhanced monitoring systems help to reduce agency costs, raise employer surplus, and facilitate market competition. Therefore, our finding implies that IT artifacts can have a prominent effect on the market structure.

Our study has several important implications. First, this study has implications for the stream of the online labor market literature by exploiting a quasi-experiment methodology. Specifically, we employ a quasiexperiment and investigate the effect of enhanced monitoring systems on both the demand and supply side. The DID model doesn't only have the advantage of controlling for self-selection bias, but also well address the time-series heterogeneity issue $[16,46]$. Therefore, our quasi-natural experiment approach allows us to provide a full picture of the impact of enhanced monitoring systems on both the demand and supply sides.

Second, our research provides some managerial implications to the platform design of online labor markets. There is a large body of research suggesting that the reputation system helps to mitigate moral hazard by serving as both a stimulus for high effort [7] and a sanctioning mechanism [15]. Meanwhile, the monitoring system is also found to be highly effective in improving agents' performance [29-31]. However, our study suggests that there exists a partial substitution relationship between these two mechanisms. Hence, our study deepens our understanding of the optimal design of online labor markets [4] by emphasizing the potential interaction effect between the reputation systems and monitoring systems.

\subsection{Limitations and further research}

We acknowledge a number of limitations of this research, which opens up avenues for future research. First, we note that complete data on the actual employer monitoring behavior is not available. However, considering there might be only part of the employers adopting the monitoring system, our estimated effect of the monitoring system tend to be conservative. Second, due to data limitations, our research only tested the effect of enhanced monitoring systems on the hourly contract market by using the observational data from only one particular online platform. Further research should retest our hypotheses under the context of other platforms or other monitoring systems. Finally, we only focused on testing the effect of IT-enabled monitoring system on employer preference and market competition. Future research could collect the reviews and ratings data regarding these awarded projects in order to explore the effect of the enhanced monitoring systems on the project final performance.

\section{References}

[1] Bresnahan, T.F., Brynjolfsson, E., and Hitt, L.M.: Information Technology, Workplace Organization, and the Demand for Skilled Labor: Firm-Level Evidence, The Quarterly Journal of Economics, 117(1), 2002, pp. 339-376.

[2] Hitt, L.M.: Information technology and firm boundaries: Evidence from panel data, Information Systems Research, 10(2), 1999, pp. 134-149.

[3] Dewan, S., and Ren, F.: Information technology and firm boundaries: Impact on firm risk and return performance, Information Systems Research, 22(2), 2011,pp. 369-388.

[4] Hong, Y., Wang, C., and Pavlou, P.A.: Comparing Open and Sealed Bid Auctions: Evidence from Online Labor Markets, Information Systems Research, 27(1), 2015, pp. 49-69.

[5] Horton, J.J.: Supply Constraints as a Market Friction: Evidence from an Online Labor Market, 2015.

[6] Srivastava, S.C., and Teo, T.S.: Contract performance in offshore systems development: Role of control mechanisms, Journal of Management Information Systems, 29(1), 2012, pp. 115-158. 
[7] Horton, J.J., and Golden, J.M.: Reputation Inflation: Evidence from an Online Labor Market, 2015.

[8] Mani, D., Barua, A., and Whinston, A.B.: An empirical analysis of the contractual and information structures of business process outsourcing relationships, Information Systems Research, 23(3-part-1), 2012, pp. 618-634.

[9] Fama, E.F.: Time, salary, and incentive payoffs in labor contracts, Journal of Labor Economics, 1991, pp. 25-44.

[10] Bajari, P., and Tadelis, S.: Incentives versus transaction costs: A theory of procurement contracts, RAND Journal of Economics, 2001, pp. 387-407.

[11] Dey, D., Fan, M., and Zhang, C.: Design and analysis of contracts for software outsourcing, Information Systems Research, 21, (1), 2010, pp. 93-114.

[12] Agrawal, A., Horton, J., Lacetera, N., and Lyons, E.: Digitization and the contract labor market: A research agenda, National Bureau of Economic Research, 2013.

[13] Chen, Y., and Bharadwaj, A.: An empirical analysis of contract structures in IT outsourcing, Information Systems Research, 20, (4), 2009, pp. 484-506.

[14] Clemons, E.K., and Chen, Y.: Making the decision to contract for cloud services: managing the risk of an extreme form of IT outsourcing, IEEE, 2011, pp. 1-10.

[15] Dellarocas, C.: Reputation mechanisms, Handbook on Economics and Information Systems, 2006, pp. 629-660.

[16] Gopal, A., and Koka, B.R.: The role of contracts on quality and returns to quality in offshore software development outsourcing, Decision Sciences, 41(3), 2010, pp. 491-516.

[17] Eisenhardt, K.M.: Agency theory: An assessment and review, Academy of management review, 14(1), 1989, pp. 57-74.

[18] Pallais, A.: Inefficient hiring in entry-level labor markets, National Bureau of Economic Research, 2013.

[19] Kokkodis, M., and Ipeirotis, P.G.: Reputation Transferability in Online Labor Markets, Management Science, 62(6), 2015, pp. 1687 - 1706.

[20] Moreno, A., and Terwiesch, C.: Doing business with strangers: Reputation in online service marketplaces, Information Systems Research, 25(4), 2014, pp. 865886.

[21] Goes, P., and Lin, M.: Does Information Really'Unravel'? Understanding Factors That Motivate Sellers to Seek Third-Party Certifications in an Online Labor Market, Understanding Factors That Motivate Sellers to Seek Third-Party Certifications in an Online Labor Market. NET Institute Working Paper, (12-02), 2012.

[22] Banerjee, A.V., and Duflo, E.: Reputation effects and the limits of contracting: A study of the Indian software industry, 1999.

[23] Susarla, A., and Krishnan, R.: Contracting in the Shadow of the Future, Available at SSRN 1975215, 2014.

[24] Gopal, A., and Sivaramakrishnan, K.: Research Note-On Vendor Preferences for Contract Types in Offshore Software Projects: The Case of Fixed Price vs. Time and Materials Contracts, Information Systems Research, 19(2), 2008, pp. 202-220.

[25] Gefen, D., Wyss, S., and Lichtenstein, Y.: Business familiarity as risk mitigation in software development outsourcing contracts, MIS quarterly, 2008, pp. 531-551.
[26] Roels, G., Karmarkar, U.S., and Carr, S.: Contracting for collaborative services, Management Science, 56(5), 2010, pp. 849-863.

[27] Susarla, A., Barua, A., and Whinston, A.B.: A transaction cost perspective of the" Software as a Service" business model, Journal of Management Information Systems, 26(2), 2009, pp. 205-240.

[28] Banker, R.D., Hwang, I., and Mishra, B.K.: Product costing and pricing under long-term capacity commitment, Journal of Management Accounting Research, 14(1), 2002, pp. 79-97.

[29] Pierce, L., Snow, D.C., and McAfee, A.: Cleaning house: The impact of information technology monitoring on employee theft and productivity, Management Science, 61(10), 2015, pp. 2299-2319.

[30] Hubbard, T.N.: The demand for monitoring technologies: the case of trucking, Quarterly Journal of Economics, 2000, pp. 533-560.

[31] Duflo, E., Hanna, R., and Ryan, S.P.: Incentives work: Getting teachers to come to school, The American Economic Review, 2012, pp. 1241-1278.

[32] Drago, R.: Incentives, pay, and performance: a study of Australian employees, Applied Economics, 23(9), 1991, pp. 1433-1446.

[33] Demiroglu, C., and James, C.M.: The role of private equity group reputation in LBO financing, Journal of Financial Economics, 96(2), 2010, pp. 306-330.

[34] Diamond, D.W.: Monitoring and reputation: The choice between bank loans and directly placed debt, Journal of political Economy, 1991, pp. 689-721.

[35] Jin, G.Z., and Kato, A.: Price, quality, and reputation: Evidence from an online field experiment, The RAND Journal of Economics, 37(4), 2006, pp. 983-1005

[36] Fombrun, C.: Reputation, Wiley Online Library, 1996.

[37] Esfahani, H.S.: Reputation and uncertainty Toward an explanation of quality problems in competitive LDC markets, Journal of Development Economics, 35(1), 1991, pp. 1-32.

[38] Allgulin, M., and Ellingsen, T.: Monitoring and pay, Journal of Labor Economics, 20, (2), 2002, pp. 201-216.

[39] Shapiro, C., and Stiglitz, J.E.: Equilibrium unemployment as a worker discipline device, The American Economic Review, 74(3), 1984, pp. 433-444.

[40] Leonard, J.S.: Carrots and sticks: Pay, supervision and turnover, National Bureau of Economic Research, Cambridge, Mass., USA, 1987.

[41] Ewing, B.T., and Payne, J.E.: The trade-off between supervision and wages: evidence of efficiency wages from the NLSY, Southern Economic Journal, 1999, pp. 424-432.

[42] Train, K.E.: Discrete choice methods with simulation, Cambridge University Press, 2009.

[43] Liu, D., Brass, D., Lu, Y., and Chen, D.: Friendships in online peer-to-peer lending: Pipes, prisms, and relational herding, MIS Quarterly, 39(3), 2015, pp. 729-742.

[44] Bertrand, M., Duflo, E., and Mullainathan, S.: How much should we trust differences-in-differences estimates?, National Bureau of Economic Research, 2002.

[45] Agrawal, A., Lacetera, N., and Lyons, E.: Does Standardized Information in Online Markets 
Disproportionately Benefit Job Applicants from Less Developed Countries?, 2014.

[46] Xue, M., Hitt, L.M., and Chen, P.-y.: Determinants and outcomes of internet banking adoption, Management Science, 57(2), 2011, pp. 291-307. 